\title{
Oligomer formation within secondary organic aerosols: equilibrium and dynamic considerations
}

\author{
E. R. Trump and N. M Donahue \\ Carnegie Mellon University, Center for Atmospheric Particle Studies, 1106 Doherty Hall, 5000 Forbes Avenue, Pittsburgh, \\ PA, 15213, USA
}

Correspondence to: E. R. Trump (etrump@andrew.cmu.edu)

Received: 22 August 2013 - Published in Atmos. Chem. Phys. Discuss.: 17 September 2013

Revised: 3 February 2014 - Accepted: 6 February 2014 - Published: 10 April 2014

\begin{abstract}
We present a model based on the volatility basis set to consider the potential influence of oligomer content on volatility driven secondary organic aerosol (SOA) yields. The implications for aerosol evaporation studies, including dilution, chamber thermo-equilibration, and thermodenuder studies, are also considered. A simplified description of oligomer formation reproduces essentially all of the broad classes of equilibrium and dynamical observations related to SOA formation and evaporation: significant oligomer content may be consistent with mass yields that increase with organic aerosol mass concentration; reversible oligomerization can explain the hysteresis between the rate of SOA formation and its evaporation rate upon dilution; and the model is consistent with both chamber thermo-equilibration studies and thermodenuder studies of SOA evaporation.
\end{abstract}

\section{Introduction}

The volatility of organic aerosols (OA) can dramatically affect their properties. Volatility governs OA mass because once a gas-phase organic compound encounters a particle, volatility controls how long that compound will remain on or in the particle; nonvolatile compounds will remain forever, whereas highly volatile compounds will evaporate in a fraction of a second. In the planetary boundary layer, gasphase organic molecules encounter particles once every few minutes (Westervelt et al., 2013), and yet almost all of them fail to stick; an organic-aerosol concentration of $1 \mu \mathrm{g} \mathrm{m}^{-3}$ is equivalent to roughly $100 \mathrm{pptv}$ of gas-phase organics. Most organics thus return to the gas phase quickly after encountering a particle. Organics in the gas phase, in turn, can and will be oxidized very quickly, and so in addition to governing the organic-aerosol concentrations, volatility can govern the lifetime of organic compounds in the atmosphere (Donahue et al., 2013).

Beginning with the work of Odum et al. (1997), and relying on the foundation developed by Pankow (1994), the theoretical basis for understanding smog-chamber secondary organic aerosol (SOA) formation experiments has been the treatment of the SOA species as semivolatile compounds. The "Odum two-product model" successfully unified seemingly inconsistent smog-chamber data that showed vastly different SOA mass yields under different conditions. More recently, the same consideration of OA volatility has been extended to primary organic aerosol (POA), where dilution (Lipsky et al., 2004) and thermodenuder (Grieshop et al., 2007) data have revealed that the large majority of POA emissions are also best classified as semivolatile (Robinson et al., 2010). The enormous range of volatilities for both POA and SOA motivated development of the volatility basis set (VBS), which segregates organics into multiple volatility "bins", typically separated by factors of 10 in organic saturation concentration $\left(C^{*}\right)$ at $300 \mathrm{~K}$, allowing consistent treatment of dilution and temperature effects on phase partitioning while permitting treatment of oxidation chemistry (aging) without an exponential explosion of product species (Donahue et al., 2006).

More recently, some developments have swung in seemingly the opposite direction. Production of high molecular weight species (oligomers) has received increasing attention in SOA studies (Kalberer et al., 2004; Tolocka et al., 2004; Heaton et al., 2007; Gao et al., 2010; Hall and Johnston, 2011), while some experiments suggest that 
diffusion constants in OA particles may be so low that organics can be trapped within particles (Vaden et al., 2010; Koop et al., 2011; Perraud et al., 2012), preventing OA systems from reaching the equilibrium suggested by partitioning theory. Oligomer formation can be split into several categories, including aqueous-phase association reactions of very low carbon-number precursors (e.g., glyoxal oxidation products) (Carlton et al., 2007; Volkamer et al., 2009; Shapiro et al., 2009; Galloway et al., 2009) and isoprene epoxides (Paulot et al., 2009) but also the association of very high molecular weight products of "classical" SOA precursors such as $\alpha$ pinene (Müller et al., 2009; Camredon et al., 2010; Hall and Johnston, 2011). These compounds are expected to be effectively nonvolatile, as they contain 20 or more carbon atoms as well as a number of polar oxygen containing functional groups.

Formation of large oligomers presents an apparent contradiction, which is the subject of this paper. Specifically, high-precision mass spectrometry suggests that a large fraction of SOA derived from $\alpha$-pinene may be in the form of oligomers that are sufficiently stable to survive collection and ionization in a mass spectrometer. However, SOA mass yields rise dramatically with increasing SOA concentrations $\left(C_{\mathrm{OA}}\right)$. In the case of $\alpha$-pinene-derived SOA, the mass yields are well below 0.05 for $C_{\mathrm{OA}} \leq 1 \mu \mathrm{g} \mathrm{m}{ }^{-3}$, but rise to exceed 0.30 for $C_{\mathrm{OA}} \geq 10^{3} \mu \mathrm{g} \mathrm{m}^{-3}$. This suggests that the corresponding volatility of most of the SOA constituents falls in that range, and specifically that most of the product molecules have $C^{*} \geq 1 \mu \mathrm{g} \mathrm{m}^{-3}$. However, even dimers, which are $\mathrm{C}_{20}$, are expected to have extremely low volatility $\left(C^{*} \leq 10^{-3} \mu \mathrm{g} \mathrm{m}^{-3}\right)$ and thus be effectively nonvolatile (Donahue et al., 2012b). This then is a most ingenious paradox. The oligomer mass fraction is reported to be as high as $50 \%$ even for high $C_{\mathrm{OA}}$, where the aerosol yield is 0.30 or more, suggesting that the mass yield of "good" monomers is at least 0.15 . However, if the oligomer formation is irreversible, and the oligomers are effectively nonvolatile, then it is not obvious why the observed mass yields would ever be less than 0.15 . Conversely, if the oligomerization is sufficiently reversible to prevent complete conversion of monomers, it is not obvious that the oligomers would survive to be observed. Our objective then is to determine whether there are conditions where reversible oligomerization can result in SOA formation consistent with these seemingly discordant observations.

\section{Oligomer formation using VBS framework}

\subsection{A simplified approach}

In this exploration, we employ a simplified description of oligmerization that is able to capture the influence of this process on volatility-driven SOA yields. We describe a single dimerization reaction in which a monomer species un- dergoes a reversible, condensed-phase reaction to produce a nonvolatile homodimer. In this most basic description, only products within a single basis-set bin act as monomer species and all products within this bin participate in the reaction. Neither of these simplifications is likely to be realistic; heterodimers involving monomers from different volatility bins seem probable (Shiraiwa et al., 2013), and it seems implausible that all species in a given volatility bin would engage in oligomerization reactions. However, confining the effect to a single bin makes it far easier to explore the features of this chemistry and our representation of it. To account for the oligomer product, we extend the VBS to include a bin for organics having an extremely low volatility. A more thorough description of SOA oligomerization would include the formation of both higher-order and hetero-oligomers from monomers of varied volatility; an additional mass bin would be needed for each oligomer product. As we shall show, constraints in addition to mass yields and even dynamical behavior would be required before undertaking this more thorough description.

The mass yield of SOA from $\alpha$-pinene ozonolysis, which is the model system for this exploration, has been studied extensively (Griffin et al., 1999; Cocker et al., 2001; Presto et al., 2005; Presto and Donahue, 2006). The yield of oligomers from similar precursors has also been studied, with recent findings suggesting both that oligomers comprise a significant portion of SOA ( $>50 \%$ by mass) and that oligomers are present even at low mass loadings (Gao et al., 2010; Hall and Johnston, 2011). In the first part of this exploration, we demonstrate that the formation of condensed-phased oligomers subject to these yield constraints (and where firstgeneration oxidation products act as the monomeric units) may be consistent with observations of SOA formation. Our findings do not contradict the conclusion that SOA formation is largely volatility driven. In fact, given the many degrees of freedom involved when deriving first-generation product yields, we find that it is trivial to describe SOA production within this framework that includes a significant amount of oligomer formation. In the second part of this work, we explore the dynamics of SOA formation and evaporation. We show that reversible oligomerization, if it strongly favors the forward reaction, would lead to a hysteresis between the rate of SOA formation and its evaporation rate upon dilution. We posit that this phenomenon could explain recent observations of delayed SOA evaporation and thus use these observations to further constrain parameters relating to the oligomerization reaction. An additional constraint is that oligomers are evident during the early stages of SOA formation (Heaton et al., 2007). In the final portion of this work, we explore the temperature dependence of oligomer formation. Specifically, we explore the evaporation of high-oligomer content SOA upon heating. 


\subsection{Equilibrium model}

Mass-based product yields from terpene ozonlysis $\left(y_{i}\right.$ in Eqs.(1) and (6)) are often determined based on SOA data from chamber experiments (Presto and Donahue, 2006). If the reaction products are formed with a fixed set of yields (in any phase), if the only process driving changes to the condensed-phase mass fraction is phase partitioning, and if the system is at equilibrium; a description of the equilibrium phase partitioning based on the volatility of these products is sufficient to reproduce the empirical SOA yield curve (Donahue et al., 2006):

$C_{i}^{\mathrm{P}}=y_{i} C_{\mathrm{ROG}}\left(1+\frac{C_{i}^{*}}{C_{\mathrm{OA}}}\right)^{-1}$.

Here, $C_{\mathrm{OA}}$ is the total organic-phase condensed mass per unit volume of air and $C_{\mathrm{ROG}}$ is the total amount of terpene reacted per unit volume of air. Any form of "aging" chemistry that changes the product yields over time in an experiment complicates this interpretation, and while an inferred set of yields $\left(y_{i}\right)$ from an experiment may fit the data, the inferred yields will likely not reflect the true volatility distribution of the reaction products.

One form of aging is ongoing oxidation chemistry, for example driven by continuous exposure to $\mathrm{OH}$ radicals (Donahue et al., 2012a). In such a case, chemistry later in an experiment can increase the aerosol mass by converting semivolatile products into relatively low-volatility products, yet an analysis based on Eq. (1) would instead infer a large yield of semivolatile products.

Another form of aging is oligomerization, where association reactions are likely to be higher order (depending on the second power of concentrations in the simplest case) and also may occur at a timescale or timescales much slower than the initial precursor oxidation timescale. Here we shall focus on oligomerization reactions occurring in the condensed phase, where high specific concentrations and solvation may allow these molecule-molecule association reactions to occur rapidly enough to influence the aerosol composition. Inclusion of a condensed-phase reaction such as dimer formation slightly alters the equilibrium framework of Eq. (1); however, it is still straightforward to parameterize the SOA mass yield.

Equation (1) continues to describe the equilibrium gasparticle partitioning of all nonreactive species. For a monomer species $(i=\mathrm{m})$ that forms a dimer product $(i=\mathrm{d})$, the formation and dissociation of the dimer per unit condensed-phase mass is given in terms of the mass fraction of the monomer and dimer in the condensed phase $\left(w_{\mathrm{m}}\right.$ and $\left.w_{\mathrm{d}}\right)$ :

$R_{\mathrm{f}}=k_{\mathrm{f}} w_{\mathrm{m}}^{2}$;

$R_{\mathrm{r}}=k_{\mathrm{r}} w_{\mathrm{d}}$ where $k_{\mathrm{f}}$ (units $\mathrm{s}^{-1}$ ) is a second-order association rate constant and $k_{\mathrm{d}}$ (units s${ }^{-1}$ ) is a first-order dissociation rate constant (the inverse lifetime of the dimer), with

$K_{\text {eq }}=k_{\mathrm{f}} / k_{\mathrm{r}}$. Thus, at equilibrium, the mass fraction of the dimer is $w_{\mathrm{d}}=K_{\mathrm{eq}} w_{\mathrm{m}}^{2}$; the ratio of monomer to dimer in the condensed phase will be tied to the monomer activity (mass fraction) in the condensed phase. Finally, the total suspended particle mass concentration of the dimer in a volume of air is given by $C_{\mathrm{d}}^{\mathrm{P}}=w_{\mathrm{d}} C_{\mathrm{OA}}$, or

$C_{\mathrm{d}}^{\mathrm{P}}=\frac{k_{\mathrm{f}}}{k_{\mathrm{r}}} w_{\mathrm{m}}^{2} C_{\mathrm{OA}}$

while the suspended particle mass concentration of the active monomer is

$C_{\mathrm{m}}^{\mathrm{P}}=\left(y_{\mathrm{m}} C_{\mathrm{ROG}}-\frac{k_{\mathrm{f}}}{k_{\mathrm{r}}} w_{\mathrm{m}}^{2} C_{\mathrm{OA}}\right)\left(1+\frac{C_{\mathrm{m}}^{*}}{C_{\mathrm{OA}}}\right)^{-1}$.

This description introduces two additional free parameters for fitting the SOA yield curves: the volatility of the monomer species and the equilibrium constant for dimerization. If a significant amount of the oligomer product is formed, the $y_{i}$ values that reproduce the SOA yield curve will be much different than those derived when only firstgeneration monomer oxidation products are considered (see Table 1).

\subsection{Dynamic model}

The timescales of the oligomerization chemistry may well span experimental timescales (minutes to hours) and so we cannot necessarily employ an equilibrium model. Consequently, we also model the dynamics of SOA formation and evaporation using the framework of the volatility basis set. For each bin, we track the mass concentrations in the vapor phase $\left(C_{i}^{\mathrm{V}}\right)$ and in the particulate phases $\left(C_{i}^{\mathrm{P}}\right)$ using

$\frac{\mathrm{d} C_{i}^{\mathrm{V}}}{\mathrm{d} t}=y_{i} C_{\mathrm{ROG}}(t)-\varphi_{i} ;$

$\frac{\mathrm{d} C_{i}^{\mathrm{P}}}{\mathrm{d} t}=\varphi_{i}-\psi_{i}$.

Here, mass concentrations are given in units $\mu \mathrm{g} \mathrm{m}^{-3}$ and the rates in units $\mu \mathrm{g} \mathrm{m}^{-3} \mathrm{~s}^{-1}$.

$C_{\mathrm{ROG}}(t)$ is the instantaneous rate of $\alpha$-pinene reacted. For this model, we assume that the condensed phase is uniform - that the composition of the particles does not vary due to diffusion within the particles or other limitations. The time constant for diffusion within a $100 \mathrm{~nm}$ particle will be less than $1 \mathrm{~h}$ as long as the condensed-phase diffusion coefficient exceeds $10^{-15} \mathrm{~cm}^{2} \mathrm{~s}^{-1}$ (Shiraiwa et al., 2011). The evidence over the full range of atmospheric conditions indicates that $\alpha$ pinene SOA is less viscous (higher diffusion coefficient) than 
Table 1. Reaction parameters that reproduce SOA yield curves for low- $\mathrm{NO}_{\mathrm{x}} \alpha$-pinene ozonolysis. Parameters are derived for two distinct oligomerization cases; for each case, the $C^{*}=100 \mu \mathrm{g} \mathrm{m}^{-3}$ bin is assumed to contain monomers that form effectively nonvolatile dimers with the indicated equilibrium constant. The "monomer only" parameters from Donahue et al. $2012 \mathrm{~b}$ are also shown.

\begin{tabular}{lrrrrrrrrrr}
\hline & $K_{\mathrm{eq}}$ & $y_{1}$ & $y_{2}$ & $y_{3}$ & $y_{4}$ & $\mathrm{y}_{5}$ & $y_{6}$ & $y_{7}$ & $y_{8}$ & y9 $_{9}$ \\
\hline$C^{*}$ & & 0.01 & 0.1 & 1 & 10 & 100 & $10^{3}$ & $10^{4}$ & $10^{5}$ & $10^{6}$ \\
Donahue et al. 2012b & 0 & 0.004 & 0.000 & 0.051 & 0.086 & 0.120 & 0.183 & 0.400 & 0.350 & 0.200 \\
Set 1 & 100 & 0.000 & 0.018 & 0.000 & 0.015 & 0.185 & 0.160 & 1.020 & - & - \\
Set 2 & $10^{3}$ & 0.004 & 0.000 & 0.010 & 0.015 & 0.140 & 0.397 & 0.828 & - & - \\
\hline
\end{tabular}

this limit: the diffusion constant for the water-soluble component exceeds $10^{-15} \mathrm{~cm}^{2} \mathrm{~s}^{-1}$ for RH $>30 \%$ (Renbaum-Wolff et al., 2013); and toluene diffuses into $\alpha$-pinene SOA particles within minutes, even at low relative humidity (Robinson et al., 2013). We also assume that the particles are large enough for curvature (Kelvin) effects to be neglected. From the discussion above, the net production of the dimer is

$\psi_{\mathrm{d}}=-\psi_{\mathrm{m}}=C_{\mathrm{OA}}\left(k_{\mathrm{f}} w_{\mathrm{m}}^{2}-k_{\mathrm{r}} w_{\mathrm{d}}\right)$.

(For species that do not participate in dimer formation, $\psi_{i}=0$.)

The aerosol net condensation rate from gas-particle partitioning $\left(\varphi_{i}\right)$ is described as

$\varphi_{i}=\operatorname{CS}\left(C_{i}^{\mathrm{V}}-w_{i} C_{i}^{*}\right)$,

where the condensation sink (CS, units of inverse time) describes the loss frequency of organic vapors to the available particle surface area (Donahue et al., 2011). The CS accounts for continuum-regime diffusion limitations and also the effects of non-unity mass accommodation coefficients. The term $w_{i}$ is the mass fraction of species $i$ in the condensedphase organics (the activity coefficient is embedded in the definition of $C^{*}$ ).

For these simulations we do not include a Kelvin term; the enormous range in volatility of the organic constituents (different $C^{*}$ values) completely overwhelms the very slight (few percent) curvature effects for particles larger than a few $10 \mathrm{~s}$ of $\mathrm{nm}$. It is established practice to "seed" SOA formation experiments with a significant number of large particles $\left(D_{\mathrm{P}}>100 \mathrm{~nm}\right)$ to minimize the effect of particle curvature on observed aerosol yields and also to ensure that the condensation sink to particles exceeds the condensation sink of the chamber walls. All simulations in this study are based on monodisperse particle populations with a constant number concentration of $10^{11} \mathrm{~m}^{-3}$. The particle diameter at each time is determined from the particulate-phase mass concentration; a density of $1 \mathrm{~g} \mathrm{~cm}^{-3}$ is used for the condensed-phase organics (consistent with normalized yield data).

\subsection{Selection of parameters for oligomerization reaction}

The reported presence of very high molecular weight (> $400 \mathrm{~g} \mathrm{~mol}^{-1}$ ) compounds in $\alpha$-pinene SOA samples sug- gests dimer formation from the association of primary oxidation products (Müller et al., 2009). Furthermore, mass spectrometry measurements suggest that the monomeric units include prominent first-generation ozonolysis products. Likely formation pathways include combination reactions to form non-covalently bonded carboxylic acid dimers and condensation reactions, such as ester formation, among many others (Hallquist et al., 2009; Camredon et al., 2010). For this exploration, we consider combination reactions of representative primary oxidation products to select parameters for a general description of oligomer formation within SOA.

Recent work from DePalma et al. (2013) suggests that the formation of dicarboxylic acid dimers in SOA is often thermodynamically favorable. We use this work as a guideline for choosing representative equilibrium constants $\left(K_{\text {eq }}\right.$ values) for the oligomerization reaction. To select a volatility bin for oligomer formation, we consider first that many SOA formation experiments are conducted over the organicaerosol mass concentration range of $1-10^{3} \mu \mathrm{g} \mathrm{m}^{-3}$ and second that some species-specific data are available in the literature. Potential monomer molecules include the following:

cis-Pinic acid: this common product of $\alpha$-pinene ozonolysis may comprise as much as $15 \%$ of the resulting organicaerosol mass yield and is known to form both homo- and heterodimers within SOA (Kuckelmann et al., 2000; Hall and Johnston, 2011). Its volatility is estimated as $C^{*} \sim 10 \mu \mathrm{g} \mathrm{m}{ }^{-3}$ based on both evaporation studies and group-contribution prediction methods (Bilde and Pandis, 2001; Pankow and Asher, 2008). The thermodynamic calculations of DePalma et al. (2013) indicate that the addition reaction that forms the cis-pinic acid homodimer has a $K_{\text {eq }}$ exceeding $10^{6}$.

Terpenylic acid: this is thought to be a common product of $\alpha$-pinene ozonolysis. Group contribution estimation methods suggest a volatility of $C^{*} \sim 10^{3} \mu \mathrm{g} \mathrm{m}^{-3}$ (Pankow and Asher, 2008). Both quantum-chemical calculations and mass spectrometric evidence indicate that it is likely to form dimers in SOA (Claeys et al., 2009; Yasmeen et al., 2010). The work of DePalma et al. (2013) suggests $K_{\text {eq }} \sim 500$ for homodimer formation.

cis-Pinonic acid: This is another common product of $\alpha$ pinene ozonolysis; it may comprise as much as $7 \%$ of the resulting mass yield (Hall and Johnston, 2011). Mass spectrometric evidence indicates that it forms both homo- and 
heterodimers within SOA (Kuckelmann et al., 2000). Vapor pressure estimation methods and observed partitioning suggest $C^{*} \sim 10^{3} \mu \mathrm{g} \mathrm{m}^{-3}$ (Pankow and Asher, 2008; Müller et al., 2012), while flow-tube experiments suggest a much lower volatility of $C^{*}<10 \mu \mathrm{g} \mathrm{m}^{-3}$ (Bilde and Pandis, 2001).

For this study, we selected the $C^{*}=100 \mu \mathrm{g} \mathrm{m}^{-3}$ bin for the monomers. This falls in the middle range of the observed aerosol mass loadings, so the condensed-phase activity and thus condensed-phase concentration of the monomer is likely to vary dramatically during SOA formation. We use the values from DePalma et al. (2013) as a guide for choosing equilibrium constants; however, as we shall show, the choice of $K_{\text {eq }}$ is constrained by aerosol mass yield observations.

\section{Model results}

\subsection{Significant oligomer content using an equilibrium VBS framework}

The first question we seek to address is simple: "can an equilibrium partitioning framework (based on the VBS) describe the sharply increasing mass yields vs. organic aerosol mass concentration (Odum plot; Odum et al., 1997) observed in chamber experiments, and at the same time be consistent with observations of oligomer mass fractions near 0.5 under these same conditions?" To answer this question we fit SOA formation data from Presto and Donahue (2006) using different oligomer equilibrium constants. For a given $K_{\text {eq }}$, we use the equilibrium model (Eqs. 1-3) to solve for the massyield parameters $\left\{y_{i}\right\}$ for a basis set of $\{0.01,0.1,1,10,100$, $\left.10^{3}, 10^{4}\right\} \mu \mathrm{g} \mathrm{m}^{-3}$. An additional bin for the dimer (which is effectively nonvolatile) has no associated $y$, as it is not produced directly from the ozonolysis chemistry. Fitting results $\left\{y_{i}\right\}$ are summarized in Table 1 for three cases: a "monomer only" case taken from earlier work (Donahue et al., 2012b) and dimer formation cases for $K_{\text {eq }}=100$ and $10^{3}$. In addition, Fig. 1 displays these results for the dimer simulations in two formats: a semilog "Odum plot" (mass yield vs. $C_{\mathrm{OA}}$ ) and a linear "growth curve" ( $C_{\mathrm{OA}}$ vs. consumed precursor). The growth curves also show the dimer concentration as a dashed curve.

In order for a significant amount of oligomer formation to occur, the forward rate must be favorable compared to the reverse rate, i.e., $K_{\text {eq }}>1$. Using $K_{\text {eq }}=100$ or $10^{3}$, we easily find parameters that reasonably reproduce the aerosol massyield curve. For both values of $K_{\text {eq }}$ there is some bowing of the predicted mass-yield curve when it is viewed as a semi$\log$ "Odum plot"; however, this bowing falls well within the range of the observations. Because the current model imposes all of the oligomerization on the $C^{*}=100 \mu \mathrm{g} \mathrm{m}^{-3}$ bin and engages all of the products in that bin in the oligomerization process, this bowing should represent the maximum excursion from a smooth curve compared with a more complex system that would allow only a fraction of the monomers in
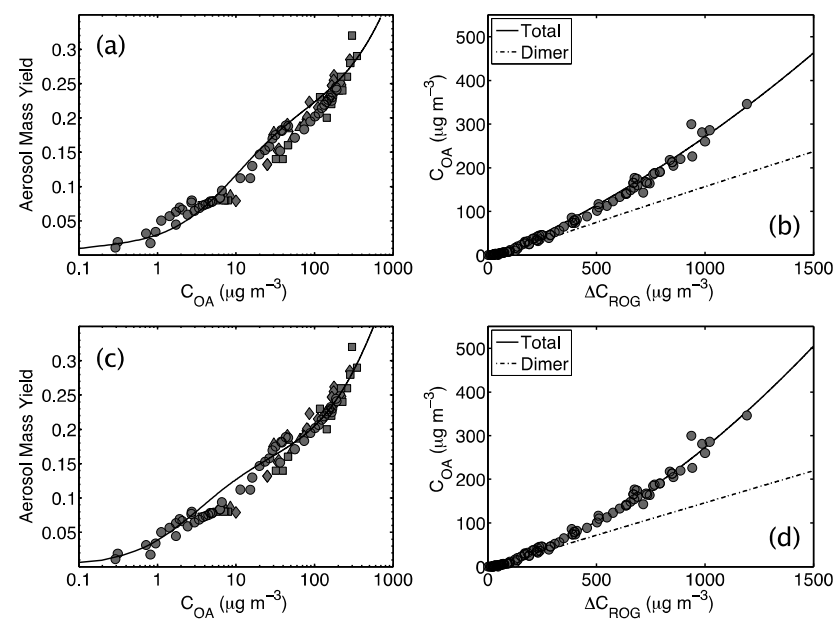

Fig. 1. (a) SOA mass yields (data from Presto and Donahue, 2006) and equilibrium fit (solid curve) for $K_{\mathrm{eq}}=100$ reaction parameters; (b) growth curve and fits of both total $C_{\mathrm{OA}}$ (solid curve) and dimer concentration (dashed curve) for $K_{\mathrm{eq}}=100$. (c) SOA mass yields for $K_{\mathrm{eq}}=10^{3} ;$ (d) growth curve for $K_{\mathrm{eq}}=10^{3}$.

each bin to engage in oligomerization chemistry. It follows that any such model could fit the data; the answer is more or less completely unconstrained by the mass-yield data alone.

The SOA growth curves in Fig. $1 b$ and d show that each set of dimerization parameters results in a large fraction, near $50 \%$, of the aerosol appearing as dimers over a wide $C_{\mathrm{OA}}$ range. The dimer fraction is very large for very low $C_{\mathrm{OA}}$, which is also consistent with limited reports in the literature. The fits in Table 1 have very low yields in bins less volatile than the monomer, and so at low $C_{\mathrm{OA}}$ the SOA consists almost entirely of a mixture of active monomer and dimer, with the condensed-phase mass-fraction of the monomer being governed by the gas-particle partitioning of the monomer. This confirms that we can reproduce the observed rising mass yields with rising $C_{\mathrm{OA}}$, even for $C_{\mathrm{OA}}$ well below the critical $C^{*}$ value of the monomer $\left(C_{\mathrm{m}}^{*}\right)$, with a high mass fraction of oligomers in the organic aerosol phase.

With dimers formed from products in the $C^{*}=$ $100 \mu \mathrm{g} \mathrm{m}^{-3}$ bin, values of $K_{\text {eq }}$ much larger than $10^{3}$ result in excessively high mass yields at low $C_{\mathrm{OA}}$ (or low yields in the monomer bin and thus low condensed-phase dimer fractions) and are thus not compatible with the joint constraints of rising mass yields and a high oligomer fraction. The reason for this behavior is straightforward: as long as $K_{\text {eq }}$ is low enough, a sufficient fraction of the "oligomerizable" material exists as monomer even in the condensed phase, and the activity of the monomer in the condensed phase is in turn controlled by its volatility. Thus, for $C_{\mathrm{OA}}<C_{\mathrm{m}}^{*}$, progressively less material is in the condensed phase as $C_{\mathrm{OA}}$ decreases. However, when $K_{\text {eq }}$ is large, essentially all of the oligomerizable material is dimer in the condensed phase, which drives the monomer condensed-phase activity to such a low level 
that almost all of the monomer vapor is taken into the particles, resulting in a plateau at a minimum aerosol mass yield - the total yield of the monomer from the initial reaction. That is the "irreversible oligomerization" limit and it is not compatible with the observed mass-yield behavior.

The values in Table 1 reveal other interesting model results. For both values of $K_{\text {eq }}$, the monomer yields in the lower- $C^{*}$ VBS bins are very low compared with the standard VBS fit. This is because essentially all of the rising mass yield is explained by oligomerization. When $C_{\mathrm{OA}}<C_{\mathrm{m}}^{*}$, the ratio of monomer in the gas and condensed phases will rise sharply with increasing $C_{\mathrm{OA}}$, while the activity of the monomer in the condensed phase will remain roughly constant, being governed almost entirely by $K_{\text {eq }}$. This can drive the rising yields by itself, as shown by Vesterinen et al. (2007). However, as the aerosol mass rises and a large fraction of the monomer partitions to the condensed phase, the oligomerization will effectively saturate. Increasing mass yields above the $C_{\mathrm{m}}^{*}$ are driven by semivolatile monomers with progressively higher volatility.

\subsection{Dynamic considerations}

\subsubsection{Evaporation upon dilution}

A third constraint on the SOA composition is how the aerosol behaves upon dilution. While the equilibrium behavior of the SOA system we are modeling will be the same during formation and dilution, dilution can occur rapidly but SOA production in chambers typically occurs on timescales on the order of an hour. Thus, dilution experiments are potentially more sensitive to processes such as oligomer decomposition.

To simulate an ideal dilution experiment in the absence of wall losses, we solve the dynamical mass-balance equations presented in Eqs. (6)-(9) for a two-stage simulation. First, $\alpha$-pinene is allowed to react with ozone for a period of time, producing products according the distributions in Table 1 . We use a first-order loss frequency of $5.8 \mathrm{~h}^{-1}$, corresponding to reaction with $700 \mathrm{ppb}$ ozone (Seinfeld and Pandis, 2006). Those products then condense to preexisting noninteracting seed particles. The initial product formation is roughly $95 \%$ complete after $1 / 2 \mathrm{~h}$ and $>99 \%$ complete after $1 \mathrm{~h}$. This growth period is simulated for $5 \mathrm{~h}$, from $t=-5 \mathrm{~h}$ to $t=0$. At that time $(t=0)$ a stepwise (instantaneous) dilution is applied with a predetermined dilution factor, and the dynamics of evaporation are simulated for an additional $5 \mathrm{~h}$. An example would be a dual-chamber experiment with a large OA mass formed in one chamber from which a small aliquot of particles and vapors (the equilibrated aerosol suspension) was transferred into a second chamber containing only pure air. This is comparable to single-particle mixing experiments in our laboratory and described elsewhere (Robinson et al., 2013).

Reversible oligomerization can lead to a hysteresis between the rate of SOA formation and its evaporation rate

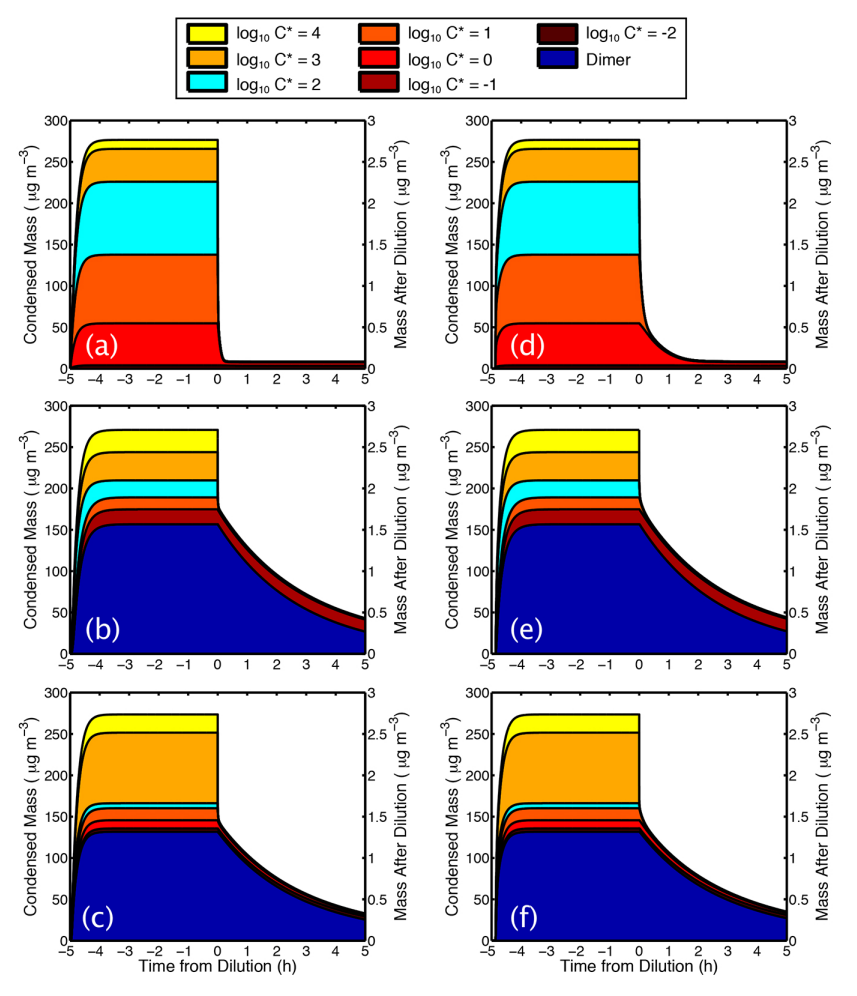

Fig. 2. Formation of SOA mass and evaporation following stepwise dilution is shown for three sets of reaction parameters and for two values of the mass accommodation coefficient. For each case, SOA mass concentration is shown by a composition stackplot. Prior to dilution, the concentration is given by the main $y$ axis; following dilution, by the secondary axis. Subplots (a) and (d) result from the "monomers only" reaction parameters given in Table 1; (b) and (e) result from "set 1" parameters; (c) and (f) result from "set 2" parameters. Subplots (a)-(c) show results for $\alpha=1$, while (d)-(f) show results for $\alpha=0.1$.

upon dilution, with $K_{\text {eq }}$ describing the separation of the associated timescales. The observations of Grieshop et al. (2007) indicate that $\alpha$-pinene SOA evaporation occurs over a few hours. In order to reproduce this behavior within our framework, a reverse rate constant on the order of $k_{\mathrm{r}}=1 \mathrm{~h}^{-1}$ or lower is needed for dimer decomposition. Since SOA equilibrium observations constrain $K_{\text {eq }}$, this consideration also influences the forward rate constant. The simulations that follow are based on $k_{\mathrm{r}}=0.4 \mathrm{~h}^{-1}$ (a $2.5 \mathrm{~h}$ dimer lifetime).

In the simulations shown in Fig. $2,10^{3} \mu \mathrm{g} \mathrm{m}^{-3}$ of $\alpha$-pinene is oxidized. At equilibrium, a bit more than $250 \mu \mathrm{g} \mathrm{m}^{-3}$ of SOA is generated, for a mass yield of about 0.25 . For each case, the system reaches this equilibrium in less than $1 \mathrm{~h}$, with no subsequent SOA growth.

The $\alpha$-pinene reaction with ozone begins $5 \mathrm{~h}$ prior to dilution. At $t=0$ a stepwise dilution by a factor of 100 occurs. Results are shown in Fig. 2 for the three cases described above (monomers only, low and high $K_{\text {eq }}$ ) and also for two values of the mass accommodation coefficient 
( $\alpha=1$ and 0.1 ). In the plots, the total concentrations of each condensed-phase species are shown as a colored stack plot. The monomer $\left(C^{*}=100 \mu \mathrm{g} \mathrm{m}^{-3}\right)$ and dimer are shown in shades of blue (cyan and dark blue) while the nonreacting semivolatile basis-set species are shown with red and yellow hues. The plots have two $y$ axes, so that the total chamber mass concentration can be read before dilution from the lefthand $y$ axis and after dilution from the right-hand $y$ axis. The second $y$ axis is scaled by the dilution factor, so that the overall plot also indicates the total mass of each constituent in a single particle (thus, a nonvolatile aerosol would appear as an uninterrupted horizontal line spanning the entire plot).

As shown in Fig. 2, the time-dependent SOA composition differs greatly for each set of reaction parameters. Unless parameters for the oligomerization reaction are known, it is not possible to predict unique product distributions based on the mass-yield data alone. When oligomer formation occurs, the rising mass yield at lower mass loadings could be explained by increased oligomer formation.

The time-dependent behavior before dilution for each simulation confirms the equilibrium findings shown above; each system appears to remain close to equilibrium for the full $5 \mathrm{~h}$ period, and there is no discernable effect of the mass accommodation coefficient. The system is controlled by the (identical) timescales of precursor loss and monomer product formation. For both dimerization cases the dimerization is also at or near equilibrium for all but the very early stages.

The time-dependent behavior after dilution is dramatically different for the "monomers only" and the oligomer cases. There is always an initial "flash" of volatile $\left(C^{*} \geq 10 \mu \mathrm{g} \mathrm{m}^{-3}\right.$ in this case) material due to the dramatic change in SOA concentration. During the quick evaporation period, a non-unity accommodation coefficient does affect the evaporation rate of semi- and low-volatility constituents $\left(C^{*} \leq 1 \mu \mathrm{g} \mathrm{m}^{-3}\right)$, and so the apparent timescale for monomer equilibration is sensitive to the accommodation coefficient as well as the condensation sink (Saleh et al., 2013). An important distinction between the "monomers only" and "oligomer" cases is the relative magnitude of the "flash". For the "monomers only" case, the flash is very large - the particles shrink dramatically and quickly - while for the oligomer case the flash is a much more modest 25-50\% drop in individual particle mass. This two-stage evaporation may be a useful diagnostic for the presence of oligomers.

Dimer decomposition controls the timescale after this initial "flash" period. For the "monomers only" case, there is no decomposition and the system rapidly reaches a new equilibrium. For the oligomer cases, the dimers decompose slowly, and so the particles gradually shrink over hours, dictated by the $2.5 \mathrm{~h}$ dimer lifetime. This is broadly consistent with the behavior reported by Grieshop et al. (2007).

\subsubsection{Evaporation upon heating}

The presence of oligomers within SOA is also likely to influence its evaporation behavior following a temperature increase. For reversible oligomerization, the oligomers are likely to be doubly sensitive to temperature, as the monomer volatility will increase but also $K_{\text {eq }}$ will drop (as $k_{\mathrm{r}}$ increases) with increasing temperature. Our intent is to determine whether significant SOA oligomer content is broadly consistent with results from temperature-dependent experiments, including smog-chamber equilibration and thermodenuder studies.

The $C^{*}$ of an organic species is a strong function of temperature that is often expressed using the ClausiusClapeyron equation:

$$
C^{*}(T)=C^{*}(300 \mathrm{~K}) \exp \left(\frac{\Delta H^{\mathrm{vap}}}{R}\left(\frac{1}{300 \mathrm{~K}}-\frac{1}{T}\right)\right)
$$

where the heat of vaporization can be approximated as $\Delta H^{\text {vap }}=\left(-6 \log _{10} C^{*}(300 \mathrm{~K})+100\right) \mathrm{kJ} \mathrm{mol}^{-1}$ and $R$ is the gas constant (Donahue et al., 2006). For other parts of this work, all $C^{*}$ values were given at $T=300 \mathrm{~K}$.

To express the temperature dependence of the reversible dimerization reaction, we first assume that the forward rate constant is temperature independent. This follows from the low apparent activation energy involved in the formation of carboxylic acid dimers (Loerting and Liedl, 1998), which drive the monomer addition reactions that we describe. Thus, we define the forward rate constant based on $K_{\text {eq }}$ at $T=300 \mathrm{~K}$. For the reverse rate constant, we describe temperature dependence using an Arrhenius-form expression (Wilcox and Bauer, 1997):

$k_{\mathrm{r}}=A \exp \left(\frac{-E_{\mathrm{a}}}{\mathrm{RT}}\right)$

where $A$ is a pre-exponential factor and $E_{\mathrm{a}}$ is the activation energy. We assume a pre-exponential factor for bimolecular dissociation reactions of $A=3 \times 10^{10} \mathrm{~s}^{-1}$. Based on dilution dynamics in Sect. 3.2.1, we arrived at $k_{\mathrm{r}}(300 \mathrm{~K})=0.4 \mathrm{~h}^{-1}$; this gives $E_{\mathrm{a}}=83 \mathrm{~kJ} \mathrm{~mol}^{-1}$.

Recent work by Saleh et al. (2013) explores the equilibrium timescales for gas-particle partitioning of SOA following a moderate $\left(22^{\circ} \mathrm{C}\right)$ temperature increase. They describe exponential evaporation of roughly $25 \%$ of the SOA mass ( $10 \%$ particle diameter) on a timescale proportional to the condensation sink of the particle population, followed by an apparent stabilization of the particle diameter over roughly $1.5 \mathrm{~h}$. We simulate a low-mass loading experiment that is similar to the smog chamber equilibration experiment shown in Fig. 3 of Saleh et al. (2013). In our simulations, $4 \mu \mathrm{g} \mathrm{m} \mathrm{m}^{-3}$ of SOA is produced at $T=283 \mathrm{~K}$ before it is subjected to a stepwise $20^{\circ}$ temperature increase at $t=0$. At this $C_{\mathrm{OA}}$, our yield parameterization ( $y_{i}$ values from "Set 2" of Table 1) results in an oligomer content of $\sim 75 \%$ (see Fig. 1d). 


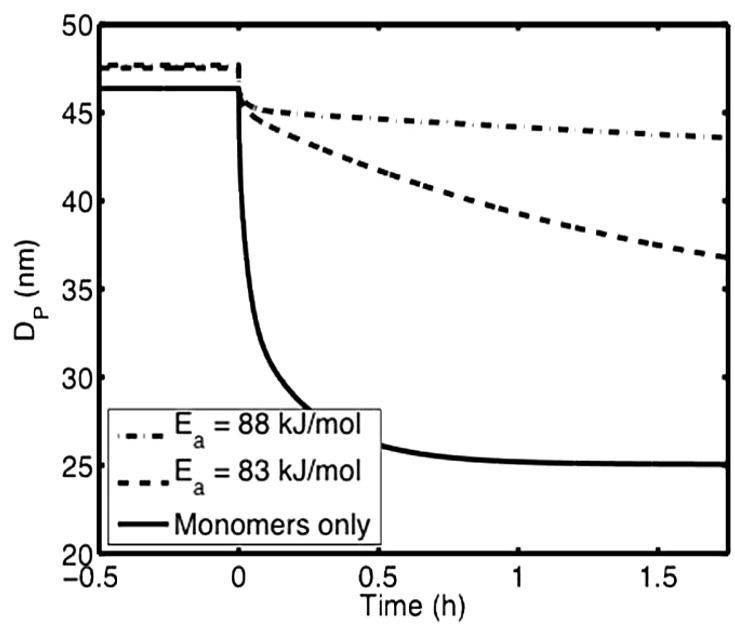

Fig. 3. Particle evaporation following a modest temperature increase for a "monomers only" case and for two oligomer cases having different dissociation $E_{\mathrm{a}}$ values. In each simulation, $C_{\mathrm{OA}} \sim 4 \mu \mathrm{g} \mathrm{m}^{-3}$ is formed at $10^{\circ} \mathrm{C}$ before being heated to $30^{\circ} \mathrm{C}$ at $t=0$. Note that the differences in initial $D_{\mathrm{P}}$ are the result of minor differences in the yield fits at this $C_{\mathrm{OA}}$. The oligomer cases are based on $K_{\mathrm{eq}}=10^{3}$ reaction parameters.

The monodisperse particle diameter corresponds to the "condensation sink diameter" used in Saleh et al. (2013). In these simulations we use a mass accommodation coefficient of 0.1, consistent with Saleh et al. (2013). Simulation results are shown for three cases: a "monomers only" case and two oligomer cases with different values for $E_{\mathrm{a}}$ of the dissociation reaction. As shown in Fig. 3, the monomers only case equilibrates rapidly, with a timescale controlled by the condensation sink and mass accommodation coefficient. This confirms the findings of Saleh et al. (2013). This rapid equilibration is analogous to the "flash" in the dilution experiments discussed above; as with those simulations, the oligomer cases in Fig. 3 show a more gradual timescale governed by dimer decomposition.

Saleh et al. (2013) report a nearly constant particle diameter following an equilibration period consistent with monomer evaporation. The oligomer decomposition that follows from $E_{\mathrm{a}}=83 \mathrm{~kJ} \mathrm{~mol}^{-1}$ is not consistent with this finding. However, a slightly higher $E_{\mathrm{a}}$ could lead to a very slow oligomer decomposition that would not necessarily be distinguishable from an equilibrium state. This is shown in Fig. 3 by the evaporation results for $E_{\mathrm{a}}=88 \mathrm{~kJ} \mathrm{~mol}^{-1}\left(k_{\mathrm{r}}(300 \mathrm{~K})\right.$ $=0.05 \mathrm{~h}^{-1} ;$ a $20 \mathrm{~h}$ dimer lifetime).

As we noted above, a clear feature distinguishing the "monomers only" case from the oligomer cases is the magnitude of the rapid change. The "monomers only" simulation results in nearly a factor of 2 change in particle diameter, whereas the oligomer cases have a much more modest initial perturbation. The final simulation shown in Fig. 3 $\left(E_{\mathrm{a}}=88 \mathrm{~kJ} \mathrm{~mol}^{-1}\right)$ combines a slight initial diameter change

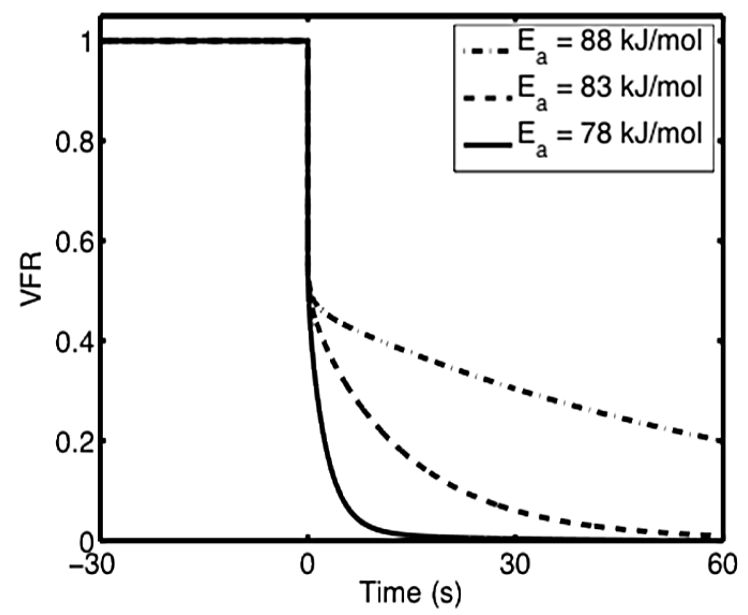

Fig. 4. Particle evaporation following a stepwise temperature increase for three values of $E_{\mathrm{a}}$. The aerosol is formed at $25^{\circ} \mathrm{C}$ before being heated to $100^{\circ} \mathrm{C}$ at $t=0$. All cases are based on $K_{\text {eq }}=10^{3}$ reaction parameters.

with a very gradual subsequent shrinkage due to decomposition; it is highly doubtful that such a slow change in mean diameter would be observable in a smog-chamber experiment, given size-dependent wall losses and other effects (Pierce et al., 2008). Overall, this behavior is very consistent with the behavior reported by Saleh et al. (2013). However, the larger yet still gradual change in diameter shown for $E_{\mathrm{a}}=83 \mathrm{~kJ} \mathrm{~mol}^{-1}$ likely would have been evident in the data presented by Saleh et al. (2013), and the $20 \mathrm{~h}$ decomposition timescale implied by the $E_{\mathrm{a}}=88 \mathrm{~kJ} \mathrm{~mol}^{-1}$ case is not obviously compatible with the slow but observable evaporation after dilution reported by Grieshop et al. (2007).

Finally, we simulate SOA evaporation upon heating to higher temperatures. The following simulations mimic thermodenuder studies in which SOA is formed at room temperature before passing through a heated tube. In a study of $\alpha$ pinene-derived SOA, An et al. (2007) found that the particles almost completely evaporate within $16 \mathrm{~s}$ at $T \geq 75^{\circ} \mathrm{C}$. We simulate the evaporation of SOA following a stepwise temperature increase $(t=0)$ from 25 to $100^{\circ} \mathrm{C}$. Consistent with An et al. (2007), $\Delta C_{\mathrm{ROG}}=620 \mu \mathrm{g} \mathrm{m}^{-3}$; with our reaction parameters, this forms $C_{\mathrm{OA}} \sim 150 \mu \mathrm{g} \mathrm{m}^{-3}$ with an oligomer content of $55 \%$ (see Fig. 1d). Figure 4 shows simulation results for three values of $E_{\mathrm{a}}\left(78,83\right.$, and $\left.88 \mathrm{~kJ} \mathrm{~mol}^{-1}\right)$. The volume fraction remaining (VFR) of the particles is defined as $D_{\mathrm{P}}^{3} / D_{\mathrm{P} 0}^{3}$ where $D_{\mathrm{P}}$ is the instantaneous particle diameter and $D_{\mathrm{P} 0}$ is taken immediately prior to the temperature increase.

When heated to $100^{\circ} \mathrm{C}$, SOA evaporation occurs quite rapidly. The monomer portion of the SOA $(45 \%)$ evaporates almost instantaneously. Dimer decomposition is also quite rapid, though the rate is sensitive to the assumed activation energy of dissociation. Even so, for the higher $E_{\mathrm{a}}$ 
$\left(88 \mathrm{~kJ} \mathrm{~mol}^{-1}\right)$, the SOA evaporation is complete after a few minutes.

While the perturbation cases considered here are all broadly consistent with a large mass fraction of reversible dimers in $\alpha$-pinene SOA, we have yet to find a solution that is fully internally consistent. Specifically, the SOA formation data as well as the isothermal dilution data are consistent with a high mass fraction (typically over $50 \%$ ) of oligomers and decomposition lifetimes of order $2.5 \mathrm{~h}$. Under these conditions, equilibrium and dynamical models reproduce the observed SOA formation, the relatively small initial "flash" of mass after dilution, and also the reported slow relaxation of particles toward the expected equilibrium after the initial flash. The same set of parameters are also consistent with the almost complete evaporation observed in thermodenuders in $16 \mathrm{~s}$ after heating to $100^{\circ} \mathrm{C}$. However, to reproduce the relaxation to a nearly constant diameter reported after a more modest $22{ }^{\circ} \mathrm{C}$ temperature jump, a much longer $(20 \mathrm{~h})$ evaporation timescale for dimers is required. It is possible that the model inconsistency could be resolved by a more detailed parameterization of oligomer formation; because properties such as $K_{\mathrm{eq}}$ and $E_{\mathrm{a}}$ will vary with reaction species (and thus the volatility of the active monomer), a more detailed model may well predict decomposition timescales that vary with mass loadings. Regardless, the consistent theme of the simulations is that the relatively modest changes to particle volume observed after perturbation are much more consistent with a high oligomer content than particles constituted primarily with monomers; those would show far too dramatic a volume change after the perturbations.

\section{Conclusions}

Using a simplified description of oligomer formation, it is possible to reproduce essentially all of the broad classes of equilibrium and dynamical observations related to SOA formation and evaporation. Systems with high oligomer content can display the increasing mass yields with increasing aerosol mass that originally inspired the "Odum interpretation" of SOA data, provided that the oligomerization is reversible and that there is thus a sufficient quantity of monomer in both the vapor and particle phases. Upon evaporation, these systems show a rapid "flash" of monomer evaporation followed by a more gradual period of slow oligomer decomposition lasting for hours, consistent with dilution data. The slow evaporation is sufficiently slow that, following a modest temperature change, particle diameters may remain nearly constant for an hour or more; yet, after a large temperature change (such as in a thermodenuder), oligomer decomposition is rapid and complete.

A consistent qualitative feature separating "monomers only" from oligomer simulations is that the rapid step changes following perturbations are much larger for monomer systems than for oligomer systems; "slow" oligomers are sluggish, and because in these simulations they account for a substantial aerosol mass fraction, the rapid response of monomers causes only small step changes to particle diameters (or mass). This may be a useful qualitative diagnostic for oligomers, and it is in fact observed.

However, a consequence of significant oligomer content is that the simple measures of SOA formation - concentrationdependent mass yields and evaporation following isothermal dilution and/or temperature perturbation - are simply not sufficient to constrain the relevant aerosol properties. We were able to obtain good quantitative agreement with such data using the drastic assumption that all species in the $C^{*}=100 \mu \mathrm{g} \mathrm{m}^{-3}$ VBS bin were "good" monomers for dimer population and that these were the only good monomers. Unfortunately, additional constraints must be employed to constrain the reactive monomer content in various volatility bins (including cross reactions to form heterodimers). Fortunately, the VBS framework, suitably modified, can easily accommodate these constraints once they are provided.

Acknowledgements. This research was supported by the National Science Foundation grant CHE1012293. E. Trump was supported by a National Science Foundation Graduate Research Fellowship.

Edited by: A. Laskin

\section{References}

An, W. J., Pathak, R. K., Lee, B. H., and Pandis, S. N.: Aerosol volatility measurement using an improved thermodenuder: Application to secondary organic aerosol, J. Aerosol Sci., 38, 305314, doi:10.1016/J.Jaerosci.2006.12.002, 2007.

Bilde, M. and Pandis, S. N.: Evaporation rates and vapor pressures of individual aerosol species formed in the atmospheric oxidation of alpha- and beta-pinene, Environ. Sci. Technol., 35, 33443349, 2001.

Camredon, M., Hamilton, J. F., Alam, M. S., Wyche, K. P., Carr, T., White, I. R., Monks, P. S., Rickard, A. R., and Bloss, W. J.: Distribution of gaseous and particulate organic composition during dark $\alpha$-pinene ozonolysis, Atmos. Chem. Phys., 10, 2893-2917, doi:10.5194/acp-10-2893-2010, 2010.

Carlton, A. G., Turpin, B. J., Altieri, K. E., Seitzinger, S., Reff, A., Lim, H. J., and Ervens, B.: Atmospheric oxalic acid and SOA production from glyoxal: Results of aqueous photooxidation experiments, Atmos. Environ., 41, 7588-7602, doi:10.1016/J.Atmosenv.2007.05.035, 2007.

Claeys, M., Iinuma, Y., Szmigielski, R., Surratt, J. D., Blockhuys, F., Van Alsenoy, C., Boge, O., Sierau, B., Gomez-Gonzalez, Y., Vermeylen, R., Van der Veken, P., Shahgholi, M., Chan, A. W. H., Herrmann, H., Seinfeld, J. H., and Maenhaut, W.: Terpenylic Acid and Related Compounds from the Oxidation of alpha-Pinene: Implications for New Particle Formation and Growth above Forests, Environ. Sci. Technol., 43, 6976-6982, doi:10.1021/Es9007596, 2009.

Cocker, D. R., Clegg, S. L., Flagan, R. C., and Seinfeld, J. H.: The effect of water on gas-particle partitioning of secondary organic 
aerosol. Part I: alpha-pinene/ozone system, Atmos. Environ., 35, 6049-6072, doi:10.1016/S1352-2310(01)00404-6, 2001.

DePalma, J. W., Horan, A. J., Hall, W. A., and Johnston, M. V.: Thermodynamics of oligomer formation: implications for secondary organic aerosol formation and reactivity, Phys. Chem. Chem. Phys., 15, 6935-6944, doi:10.1039/C3cp44586k, 2013.

Donahue, N. M., Robinson, A. L., Stanier, C. O., and Pandis, S. N.: Coupled partitioning, dilution, and chemical aging of semivolatile organics, Environ. Sci. Technol., 40, 02635-02643, doi:10.1021/Es052297c, 2006.

Donahue, N. M., Trump, E. R., Pierce, J. R., and Riipinen, I.: Theoretical constraints on pure vapor-pressure driven condensation of organics to ultrafine particles, Geophys. Res. Lett., 38, L16801, doi:10.1029/2011g1048115, 2011.

Donahue, N. M., Henry, K. M., Mentel, T. F., Kiendler-Scharr, A., Spindler, C., Bohn, B., Brauers, T., Dorn, H. P., Fuchs, H., Tillmann, R., Wahner, A., Saathoff, H., Naumann, K. H., Mohler, O., Leisner, T., Müller, L., Reinnig, M. C., Hoffmann, T., Salo, K., Hallquist, M., Frosch, M., Bilde, M., Tritscher, T., Barmet, P., Praplan, A. P., DeCarlo, P. F., Dommen, J., Prevot, A. S. H., and Baltensperger, U.: Aging of biogenic secondary organic aerosol via gas-phase OH radical reactions, P. Natl. Acad. Sci. USA, 109, 13503-13508, doi:10.1073/Pnas.1115186109, 2012a.

Donahue, N. M., Kroll, J. H., Pandis, S. N., and Robinson, A. L.: A two-dimensional volatility basis set - Part 2: Diagnostics of organic-aerosol evolution, Atmos. Chem. Phys., 12, 615-634, doi:10.5194/acp-12-615-2012, 2012b.

Donahue, N. M., Chuang, W., Epstein, S. A., Kroll, J. H., Worsnop, D. R., Robinson, A. L., Adams, P. J., and Pandis, S. N.: Why do organic aerosols exist? Understanding aerosol lifetimes using the two-dimensional volatility basis set, Environ. Chem., 10, 151157, doi:10.1071/EN13022, 2013.

Galloway, M. M., Chhabra, P. S., Chan, A. W. H., Surratt, J. D., Flagan, R. C., Seinfeld, J. H., and Keutsch, F. N.: Glyoxal uptake on ammonium sulphate seed aerosol: reaction products and reversibility of uptake under dark and irradiated conditions, Atmos. Chem. Phys., 9, 3331-3345, doi:10.5194/acp-9-3331-2009, 2009.

Gao, Y. Q., Hall, W. A., and Johnston, M. V.: Molecular Composition of Monoterpene Secondary Organic Aerosol at Low Mass Loading, Environ. Sci. Technol., 44, 7897-7902, doi:10.1021/Es101861k, 2010.

Grieshop, A. P., Donahue, N. M., and Robinson, A. L.: Is the gas-particle partitioning in alpha-pinene secondary organic aerosol reversible?, Geophys. Res. Lett., 34, L14810, doi:10.1029/2007g1029987, 2007.

Griffin, R. J., Cocker, D. R., Seinfeld, J. H., and Dabdub, D.: Estimate of global atmospheric organic aerosol from oxidation of biogenic hydrocarbons, Geophys. Res. Lett., 26, 2721-2724, 1999.

Hall, W. A. and Johnston, M. V.: Oligomer Content of alpha-Pinene Secondary Organic Aerosol, Aerosol Sci. Technol., 45, 37-45, doi:10.1080/02786826.2010.517580, 2011.

Hallquist, M., Wenger, J. C., Baltensperger, U., Rudich, Y., Simpson, D., Claeys, M., Dommen, J., Donahue, N. M., George, C., Goldstein, A. H., Hamilton, J. F., Herrmann, H., Hoffmann, T., Iinuma, Y., Jang, M., Jenkin, M. E., Jimenez, J. L., Kiendler-Scharr, A., Maenhaut, W., McFiggans, G., Mentel, Th. F., Monod, A., Prévôt, A. S. H., Seinfeld, J. H., Surratt, J. D.,
Szmigielski, R., and Wildt, J.: The formation, properties and impact of secondary organic aerosol: current and emerging issues, Atmos. Chem. Phys., 9, 5155-5236, doi:10.5194/acp-9-51552009, 2009.

Heaton, K. J., Dreyfus, M. A., Wang, S., and Johnston, M. V.: Oligomers in the early stage of biogenic secondary organic aerosol formation and growth, Environ. Sci. Technol., 41, 61296136, doi:10.1021/Es070314n, 2007.

Kalberer, M., Paulsen, D., Sax, M., Steinbacher, M., Dommen, J., Prevot, A. S. H., Fisseha, R., Weingartner, E., Frankevich, V., Zenobi, R., and Baltensperger, U.: Identification of polymers as major components of atmospheric organic aerosols, Science, 303, 1659-1662, doi:10.1126/Science.1092185, 2004.

Koop, T., Bookhold, J., Shiraiwa, M., and Pöschl, U.: Glass transition and phase state of organic compounds: dependency on molecular properties and implications for secondary organic aerosols in the atmosphere, Phys. Chem. Chem. Phys., 13, 19238-19255, doi:10.1039/C1cp22617g, 2011.

Kuckelmann, U., Warscheid, S., and Hoffmann, T.: On-line characterization of organic aerosols formed from biogenic precursors using atmospheric pressure chemical ionization mass spectrometry, Anal. Chem., 72, 1905-1912, doi:10.1021/Ac991178a, 2000.

Lipsky, E. M., Pekney, N. J., Walbert, G. F., O’Dowd, W. J., Freeman, M. C., and Robinson, A.: Effects of dilution sampling on fine particle emissions from pulverized coal combustion, Aerosol Sci. Technol., 38, 574-587, doi:10.1080/02786820490479851, 2004.

Loerting, T. and Liedl, K. R.: Toward elimination of discrepancies between theory and experiment: Double proton transfer in dimers of carboxylic acids, J. Am. Chem. Soc., 120, 1259512600, doi:10.1021/Ja9817390, 1998.

Müller, L., Reinnig, M. C., Hayen, H., and Hoffmann, T.: Characterization of oligomeric compounds in secondary organic aerosol using liquid chromatography coupled to electrospray ionization Fourier transform ion cyclotron resonance mass spectrometry, Rapid Commun. Mass Sp., 23, 971-979, doi:10.1002/Rcm.3957, 2009.

Müller, L., Reinnig, M.-C., Naumann, K. H., Saathoff, H., Mentel, T. F., Donahue, N. M., and Hoffmann, T.: Formation of 3-methyl1,2,3-butanetricarboxylic acid via gas phase oxidation of pinonic acid - a mass spectrometric study of SOA aging, Atmos. Chem. Phys., 12, 1483-1496, doi:10.5194/acp-12-1483-2012, 2012.

Odum, J. R., Jungkamp, T. P. W., Griffin, R. J., Forstner, H. J. L., Flagan, R. C., and Seinfeld, J. H.: Aromatics, reformulated gasoline, and atmospheric organic aerosol formation, Environ. Sci. Technol., 31, 1890-1897, doi:10.1021/Es9605351, 1997.

Pankow, J. F.: An Absorption-Model of Gas-Particle Partitioning of Organic-Compounds in the Atmosphere, Atmos. Environ., 28, 185-188, 1994.

Pankow, J. F. and Asher, W. E.: SIMPOL.1: a simple group contribution method for predicting vapor pressures and enthalpies of vaporization of multifunctional organic compounds, Atmos. Chem. Phys., 8, 2773-2796, doi:10.5194/acp-8-27732008, 2008.

Paulot, F., Crounse, J. D., Kjaergaard, H. G., Kurten, A., St Clair, J. M., Seinfeld, J. H., and Wennberg, P. O.: Unexpected Epoxide Formation in the Gas-Phase Photooxidation of Isoprene, Science, 325, 730-733, doi:10.1126/Science.1172910, 2009. 
Perraud, V., Bruns, E. A., Ezell, M. J., Johnson, S. N., Yu, Y., Alexander, M. L., Zelenyuk, A., Imre, D., Chang, W. L., Dabdub, D., Pankow, J. F., and Finlayson-Pitts, B. J.: Nonequilibrium atmospheric secondary organic aerosol formation and growth, P. Natl. Acad. Sci. USA, 109, 2836-2841, doi:10.1073/Pnas.1119909109, 2012.

Pierce, J. R., Engelhart, G. J., Hildebrandt, L., Weitkamp, E. A., Pathak, R. K., Donahue, N. M., Robinson, A. L., Adams, P. J., and Pandis, S. N.: Constraining particle evolution from wall losses, coagulation, and condensation-evaporation in smogchamber experiments: Optimal estimation based on size distribution measurements, Aerosol Sci. Tech., 42, 1001-1015, doi:10.1080/02786820802389251, 2008.

Presto, A. A. and Donahue, N. M.: Investigation of alphapinene plus ozone secondary organic aerosol formation at low total aerosol mass, Environ. Sci. Technol., 40, 3536-3543, doi:10.1021/Es052203z, 2006.

Presto, A. A., Hartz, K. E. H., and Donahue, N. M.: Secondary organic aerosol production from terpene ozonolysis. 2. Effect of $\mathrm{NO}_{\mathrm{x}}$ concentration, Environ. Sci. Technol., 39, 7046-7054, doi:10.1021/Es050400s, 2005.

Renbaum-Wolff, L., Grayson, J. W., Bateman, A. P., Kuwata, M., Sellier, M., Murray, B. J., Shilling, J. E., Martin, S. T., and Bertram, A. K.: Viscosity of alpha-pinene secondary organic material and implications for particle growth and reactivity, P. Natl. Acad. Sci. USA, 110, 8014-8019, doi:10.1073/Pnas.1219548110, 2013.

Robinson, A. L., Grieshop, A. P., Donahue, N. M., and Hunt, S. W.: Updating the Conceptual Model for Fine Particle Mass Emissions from Combustion Systems, JAPCA J. Air Waste Ma., 60, 1204-1222, doi:10.3155/1047-3289.60.10.1204, 2010.

Robinson, E. S., Saleh, R., and Donahue, N. M.: Organic Aerosol Mixing Observed by Single-Particle Mass Spectrometry, J. Phys. Chem. A, 51, 13935-13945, 2013.

Saleh, R., Donahue, N. M., and Robinson, A. L.: Time scales for gas-particle partitioning equilibration of secondary organic aerosol formed from alpha-pinene ozonolysis, Environ. Sci. Technol., 47, 5588-5594, doi:10.1021/es400078d, 2013.

Seinfeld, J. H. and Pandis, S. N.: Atmospheric Chemistry and Physics - From Air Pollution to Climate Change (2nd Edn.), John Wiley \& Sons, New York, 2006.

Shapiro, E. L., Szprengiel, J., Sareen, N., Jen, C. N., Giordano, M. R., and McNeill, V. F.: Light-absorbing secondary organic material formed by glyoxal in aqueous aerosol mimics, Atmos. Chem. Phys., 9, 2289-2300, doi:10.5194/acp-9-2289-2009, 2009.
Shiraiwa, M., Ammann, M., Koop, T., and Pöschl, U.: Gas uptake and chemical aging of semisolid organic aerosol particles, P. Natl. Acad. Sci. USA, 108, 11003-11008, doi:10.1073/Pnas.1103045108, 2011.

Shiraiwa, M., Yee, L. D., Schilling, K. A., Loza, C. L., Craven, J. S., Zuend, A., Ziemann, P. J., and Seinfeld, J. H.: Size distribution dynamics reveal particle-phase chemistry in organic aerosol formation, P. Natl. Acad. Sci. USA, 110, 11746-11750, doi:10.1073/Pnas.1307501110, 2013.

Tolocka, M. P., Jang, M., Ginter, J. M., Cox, F. J., Kamens, R. M., and Johnston, M. V.: Formation of oligomers in secondary organic aerosol, Environ. Sci. Technol., 38, 1428-1434, doi:10.1021/Es035030r, 2004.

Vaden, T. D., Song, C., Zaveri, R. A., Imre, D., and Zelenyuk, A.: Morphology of mixed primary and secondary organic particles and the adsorption of spectator organic gases during aerosol formation, P. Natl. Acad. Sci. USA, 107, 6658-6663, doi:10.1073/Pnas.0911206107, 2010.

Vesterinen, M., Lehtinen, K. E. J., Kulmala, M., and Laaksonen, A.: Effect of particle phase oligomer formation on aerosol growth, Atmos. Environ., 41, 1768-1776, doi:10.1016/J.Atmosenv.2006.10.024, 2007.

Volkamer, R., Ziemann, P. J., and Molina, M. J.: Secondary Organic Aerosol Formation from Acetylene $\left(\mathrm{C}_{2} \mathrm{H}_{2}\right)$ : seed effect on SOA yields due to organic photochemistry in the aerosol aqueous phase, Atmos. Chem. Phys., 9, 1907-1928, doi:10.5194/acp9-1907-2009, 2009.

Westervelt, D. M., Pierce, J. R., Riipinen, I., Trivitayanurak, W., Hamed, A., Kulmala, M., Laaksonen, A., Decesari, S., and Adams, P. J.: Formation and growth of nucleated particles into cloud condensation nuclei: model-measurement comparison, Atmos. Chem. Phys., 13, 7645-7663, doi:10.5194/acp-13-76452013, 2013.

Wilcox, C. F. and Bauer, S. H.: The dissociation of dimeric aliphatic acids: Energetics and relaxation kinetics, J. Chem. Phys., 107, 5794-5803, doi:10.1063/1.474339, 1997.

Yasmeen, F., Vermeylen, R., Szmigielski, R., Iinuma, Y., Böge, O., Herrmann, H., Maenhaut, W., and Claeys, M.: Terpenylic acid and related compounds: precursors for dimers in secondary organic aerosol from the ozonolysis of $\alpha$ - and $\beta$-pinene, Atmos. Chem. Phys., 10, 9383-9392, doi:10.5194/acp-10-9383-2010, 2010. 